\title{
Size discrepancies in molars and first key to optimal occlusion
}

\author{
Ahmet Arif Celebi ${ }^{1}$, Sam H. Lee ${ }^{2}$, Chung How Kau ${ }^{1}$
}

Correspondence: Dr. Chung How Kau

Email: ckau@uab.edu

\begin{abstract}
'Department of Orthodontics, University of Alabama at Birmingham, School of Dentistry, Birmingham, Alabama, USA,

'University of Alabama at Birmingham,

School of Dentistry, Birmingham, Alabama, USA
\end{abstract}

\section{ABSTRACT}

Objective: The aim of this research project was to determine whether the sizes of the first molars allow clinicians to achieve the first goal of an ideal clinical outcome. Material and Methods: Seventy-eight sets of dental casts that have been presented to the American Board of Orthodontics were evaluated. A Boley gauge was used to measure the length from the mesiobuccal cusp to the distobuccal cusp of the maxillary first molar and the length from the mesiobuccal groove of the mandibular first molar to the occlusal embrasure between the mandibular first and second molars. These two measurements were taken on both sides of each set of dental casts for a total of four measurements per set. Results: The maxillary measurements ranged from 3.6 to $6.9 \mathrm{~mm}$ with an average of $5.2 \mathrm{~mm}$. The mandibular measurements ranged from 5.0 to $8.0 \mathrm{~mm}$ with an average of $6.5 \mathrm{~mm}$. The data were tested for normality and found to be equally distributed. A t-test revealed significant differences in tooth sizes between maxillary and mandibular first molars on both sides. On average, the mesiodistal length measured on maxillary first molars was about $80 \%$ of that of their mandibular counterparts. Only 5 of the 78 sets of dental casts evaluated had equal maxillary and mandibular measurements on one side (either left or right), and none of them had equal measurements on both sides. Conclusion: Clinicians have to understand that tooth size discrepancies do exist in patients and that these discrepancies make the completion of a perfect case challenging.

Key words: Dental occlusion, mandible, maxilla, molar tooth, permanent dentition

\section{INTRODUCTION}

According to Angle's definition, a correct molar relationship exists when the upper first molar's mesiobuccal cusp occludes into the buccal groove of the lower first molar, and the teeth are arranged on a smoothly curving line of occlusion. ${ }^{[1]}$ If this relationship occurs, a normal occlusion is present. The concept of angle was supplemented by the "Six Keys to Normal Occlusion" by Andrews. ${ }^{[2]}$ In his description, the first key, molar inter-arch relationship, is not very different from Angle`s definition except

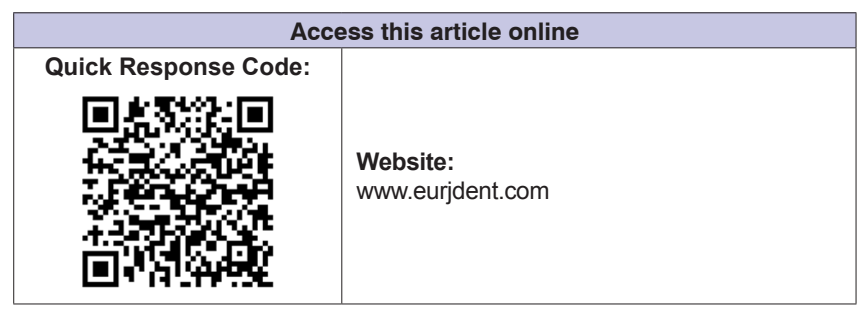

that Andrews stated the distal marginal ridge of the upper first molar must be occluded with mesial marginal ridge of lower second molar [Figure 1].

In 1998, the American Board of Orthodontics (ABO) introduced the objective grading system (OGS) or cast/radiographic evaluation, a standard method to evaluate finished cases considering eight criteria (alignment, marginal ridges, buccolingual inclination, occlusal relationships, occlusal contacts, overjet, interproximal contacts, and root angulation)

This is an open access article distributed under the terms of the Creative Commons Attribution-NonCommercial-ShareAlike 3.0 License, which allows others to remix, tweak, and build upon the work non-commercially, as long as the author is credited and the new creations are licensed under the identical terms.

For reprints contact: reprints@medknow.com

How to cite this article: Celebi AA, Lee $\mathrm{SH}, \mathrm{Kau} \mathrm{CH}$. Size discrepancies in molars and first key to optimal occlusion. Eur J Dent 2017;11:250-2.

DOI: 10.4103/ejd.ejd_339_16 
in dental casts and panoramic radiographs. ${ }^{[3]}$ The first molar relationship and cusp to fossa relationship are an important goal of the OGS.

The purpose of the present study was to determine whether the sizes of the first molars allow clinicians to achieve the first goal of an ideal clinical outcome on the cast models were presented to the $\mathrm{ABO}$.

\section{MATERIALS AND METHODS}

The research material consisted of 78 set diagnostic cast models that had been presented at an exit examination at the University of Alabama Birmingham. In addition, these cases had been examined and passed the clinical component of the ABO. Final casts were obtained from the records of patients who have normal appearing teeth. No large restorations or fixed prosthodontic replacement were present. Class I canine and premolar relationships were also present. A boley gauge was used to measure the length from the mesiobuccal cusp to the distobuccal cusp of the maxillary first molar (mbdbmax) and the length from the mesiobuccal groove of the mandibular first molar to the occlusal embrasure (mboemand) between the mandibular first and second molars. These two measurements were taken on both sides of each set of dental casts for a total of four measurements per set [Table 1].

Statistical analysis of data was performed by means of SPSS v. 19 software (SPSS Inc., Chicago, IL, USA). A paired sample $t$-test revealed significant differences in tooth sizes between the reference points on maxillary and mandibular first molars on both sides. The level of significance was $P<0.05$.

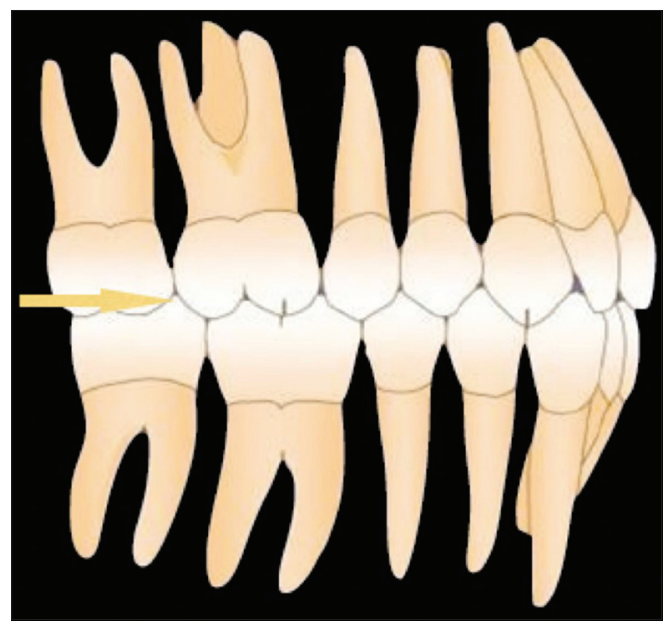

Figure 1: Molar relationships with an excellent Class I occlusion described by Andrews

\section{RESULTS}

The results are presented in Table 1 . The maxillary measurements ranged from 3.6 to $6.9 \mathrm{~mm}$ with an average of $5.2 \mathrm{~mm}$. The mandibular measurements ranged from 5.0 to $8.0 \mathrm{~mm}$ with an average of $6.5 \mathrm{~mm}$. On average, the mesiodistal length measured on maxillary first molars was about $80 \%$ of that of their mandibular counterparts. Only 5 of the 78 sets of dental casts evaluated had equal maxillary and mandibular measurements on one side (either left or right), and none of them had equal measurements on both sides [Figure 2].

\section{DISCUSSION AND CLINICAL IMPLICATION}

Tooth size discrepancies play an important role in precise planning and achieving the best possible outcome. ${ }^{[4,5]}$ To achieve the ideal Class I molar relationship that was described by Andrews, the length from the mesiobuccal cusp to the distobuccal cusp of the maxillary first molar, and the length from the mesiobuccal groove of the mandibular

\begin{tabular}{lcccc}
\multicolumn{6}{l}{ Table 1: Distance of reference points $(\mathbf{m m})$} \\
\hline Measurements & $\boldsymbol{n}$ & Mean & SD & $\boldsymbol{P}$ \\
\hline mbdbmax right (a) & 78 & 5.12 & 0.68 & $0.004^{*}$ \\
mboemand right (a1) & 78 & 6.41 & 0.55 & \\
mbdbmax left (b) & 78 & 5.22 & 0.66 & $0.003^{*}$ \\
mboemand left (b1) & 78 & 6.52 & 0.54 & \\
a/a1 & 78 & 80.3 & 10.7 & 0.93 \\
b/b1 & 78 & 80.4 & 10.2 & \\
\hline
\end{tabular}

*Statistically significant for $P<0.05$. SD: Standard deviation

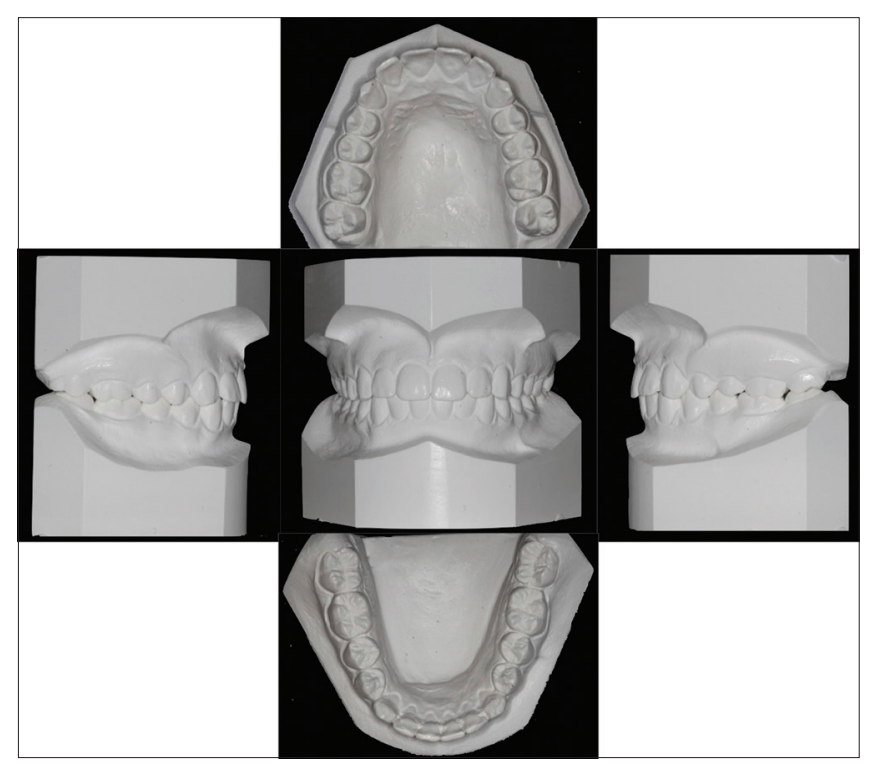

Figure 2: Molar relationships with a Class I occlusion case was presented and passed in the American Board of Orthodontics 
first molar to the occlusal embrasure between the mandibular first and second molars should be equal. Unfortunately, It is not possible every time, even if we have excellent Class I relationships in canine and premolar areas. This presents a significant problem.

In this study, the following three recommendations are suggested because only $6 \%$ of the sample would achieve Andrew's goal.

1. If there is no difference, every effort should be used to finish the case with excellent Class I occlusion. Anchorage management is critical

2. If the distance between the mandibular first molar reference points is a little bigger than distance between the maxillary reference points, the clinician can biomechanically create a little mesiobuccal rotational movement to maxillary first molar. This will allow the maxillary first molar to occupy more space

3. If the distance between the mandibular first molar reference points is much more bigger than distance between the maxillary reference points, a carefully clinical judgement has to be made. Instead of finishing the occlusion with the mesiobuccal cusp of the maxillary molar in the mesiobuccal cusp of the mandibular molar, it is suggested the distobuccal cusp of the maxillary molar be finished in the embrasure between the mandibular first and second molar [Figure 3]. This position will allow the maxillary second molars and second bicuspids to be finished in an ideal cusp to fossa position.

\section{CONCLUSION}

Tooth-size discrepancy must be taken into consideration when planning orthodontic care, and clinicians have to understand that tooth size discrepancies do exist in patients and that these discrepancies make the completion of a perfect case challenging. In this article,

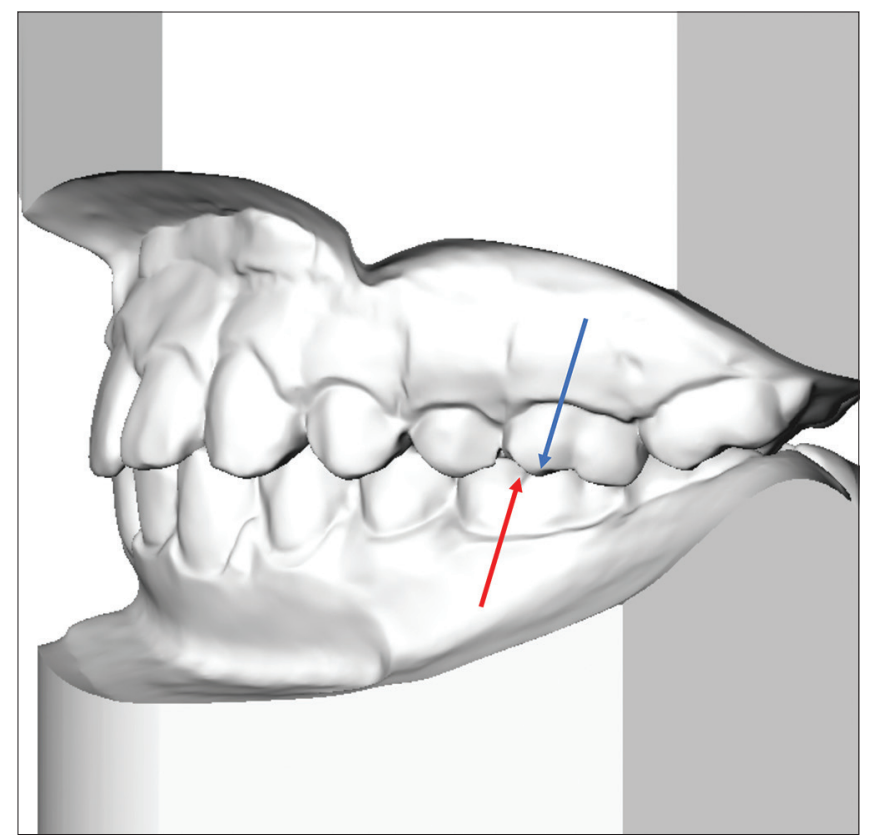

Figure 3: Clinical tip to finish the case for first molar position

clinical suggestions have been made to better finish orthodontic cases.

\section{Financial support and sponsorship}

Nil.

\section{Conflicts of interest}

There are no conflicts of interest.

\section{REFERENCES}

1. Angle EH. The Upper First Permanent Molar as a Basis of Diagnosis. Items of Interest; June, 1906.

2. Andrews LF. The six keys to normal occlusion. Am J Orthod 1972;62:296-309.

3. Casko JS, Vaden JL, Kokich VG, Damone J, James RD, Cangialosi TJ, et al. Objective grading system for dental casts and panoramic radiographs. American Board of Orthodontics. Am J Orthod 1998;114:589-99.

4. Akyalçin S, Dogan S, Dinçer B, Erdinc AM, Oncag G. Bolton tooth size discrepancies in skeletal class I individuals presenting with different dental angle classifications. Angle Orthod 2006;76:637-43.

5. Santoro M, Ayoub ME, Pardi VA, Cangialosi TJ. Mesiodistal crown dimensions and tooth size discrepancy of the permanent dentition of Dominican Americans. Angle Orthod 2007;70:303-7. 